\title{
The Roman High- and Low-Avoidance Rat Lines Differ in the Acquisition, Maintenance, Extinction, and Reinstatement of Intravenous Cocaine Self-Administration
}

\author{
Liana Fattore', Giovanna Piras², Maria G Corda ${ }^{2}$ and Osvaldo Giorgi*,2 \\ IInstitute of Neuroscience CNR, Section of Cagliari, Italy; ${ }^{2}$ Department of Toxicology, University of Cagliari, Italy
}

\begin{abstract}
The selective breeding of Roman high- (RHA) and low-avoidance (RLA) rats for, respectively, rapid vs extremely poor acquisition of avoidant behavior in a shuttlebox has produced two phenotypes that differ in temperament traits, in mesocortical/mesolimbic dopamine system function, and in the behavioral and neurochemical responses to the acute and repeated administration of psychostimulants and opiates. The phenotypic traits of the RHA line predict higher susceptibility, compared with RLA rats, to the reinforcing properties of addictive substances like cocaine. The present study was designed to compare the acquisition, maintenance, reinstatement of drugseeking after long-term extinction, and reacquisition of intravenous cocaine self-administration (SA) behavior in the Roman lines. Compared with RLA rats, the rates of responding during cocaine SA acquisition were higher, extinction from cocaine SA was prolonged, and drug-induced reinstatement of cocaine-seeking behavior was more robust in RHA rats. Moreover, only RHA rats reacquired extinguished lever-pressing activity when a low reinforcing dose of cocaine was available. These findings are consistent with the view that subjects with genetically determined high responsiveness to the acute and chronic (ie, sensitizing) effects of psychostimulants, such as RHA rats, also display a higher propensity to self-administer cocaine. Further comparative studies in the Roman lines, using SA paradigms that distinguish mere drug-taking from the compulsive and uncontrolled drug use that characterizes addiction in humans, may eventually help to characterize the relationships among genotype, temperament traits, and neurobiological mechanisms involved in the individual vulnerability to cocaine addiction.
\end{abstract}

Neuropsychopharmacology (2009) 34, I09|-I I01; doi: 10.1038/npp.2008.43; published online I6 April 2008

Keywords: cocaine self-administration; extinction and reinstatement; roman high- and low-avoidance rats; genetic selection; mesocortical and mesolimbic dopaminergic systems

\section{INTRODUCTION}

The transition from casual and recreational drug use to compulsive, uncontrolled, drug-seeking and drug-taking as well as the increased vulnerability to relapse to drug use after detoxification have long been recognized as cardinal mechanisms in the pathogenesis of addictive disorders (American Psychiatric Association, 1994; O’Brien, 1997). As regards cocaine addiction, the high frequency of relapse to uncontrolled drug use, even after long periods of abstinence (O'Brien, 1997; McLellan et al, 2000), has led to the hypothesis that the intensity of cocaine craving induced by re-exposure to the drug itself or to drug-paired cues undergoes a time-dependent increase during abstinence (Gawin and Kleber, 1986). Accordingly, preclinical studies using stimulus-induced reinstatement of cocaine-

*Correspondence: Dr O Giorgi, Department of Toxicology, University of Cagliari, Via Ospedale 72, Cagliari 09124, Italy, Tel: + (39 070) 675 8631; Fax: + (39 070) 675 8612, E-mail: giorgi@unica.it

Received 12 November 2007; revised 4 February 2008; accepted 16 February 2008 seeking behavior to model relapse in humans have shown that the intensity of the behavioral responses to cocaine or cocaine-related cues increases over 1-3 months of withdrawal (Tran-Nguyen et al, 1998; Grimm et al, 2001).

Preclinical research and brain imaging studies in human addicts have established that the mesocortical/mesolimbic dopaminergic pathways originating in the ventral tegmental area and projecting to the nucleus accumbens (NAc), the medial prefrontal cortex (mPFC), and other limbic areas are critically involved in the motivational effects of psychostimulants (Di Chiara and Imperato, 1988; Koob et al, 2004; Wise, 2004; Kalivas and Volkow, 2005; Vanderschuren and Everitt, 2005). It has been proposed that these neural circuits encode and associate information about a primary reinforcer like cocaine with motivated behavior and/or environmental stimuli (Everitt and Wolf, 2002; Schultz, 2002; Hollander and Carelli, 2007). Adaptive changes in this neural circuitry are also believed to underlie the long-term increment in the locomotor activation of rodents (ie, behavioral sensitization) elicited by the repeated exposure to cocaine (Vanderschuren and Kalivas, 2000; Nestler, 2001; Li et al, 2004; Vezina, 2004). There is also experimental 
evidence that sensitization-like processes may account for the compulsive pattern of drug-seeking and the vulnerability to relapse that persists long after the cessation of psychostimulant use in humans (Robinson and Berridge, 2003).

Only about $15-20 \%$ of people exposed to drugs eventually become addicted and are at high risk of relapsing to drug use (Anthony et al, 1994), suggesting a remarkable individual variation in the risk that casual users of addictive drugs may evolve to a condition of uncontrollable drug use. It is well established that phenotypic variation in the liability to addiction is strongly influenced by differences in individual genotypes and by their interactions with different environmental conditions (Reich et al, 1999; Vanyukov and Tarter, 2000; Uhl et al, 2002). Genetic factors also influence personality traits and temperament clusters, including disinhibition/impulsivity and sensation/novelty seeking which, in turn, have been identified as vulnerability factors for substance use disorders (Bardo et al, 1996; Ebstein et al, 2000; Verheul and van den Brink, 2000; Helmus et al, 2001). These findings have spurred the use of a wide variety of inbred strains and outbred lines of rodents as valid models to investigate genetically determined differences in behavioral and neurochemical traits related to addictive disorders (Kosten et al, 1997; Crabbe 2002; Laakso et al, 2002; Fernández-Teruel et al, 2002; McClung and Nestler, 2003; Deiana et al, 2007).

The Roman high- (RHA) and low-avoidance (RLA) rat lines were selected for, respectively, rapid $v s$ poor acquisition of two-way active avoidance in the shuttle-box (Broadhurst and Bignami, 1965; Driscoll and Bättig, 1982; Fernández-Teruel et al, 2002; Giorgi et al, 2007). Several relevant behavioral and neurochemical differences between the two lines have been identified along the selective breeding process. Thus, compared with their RLA counterparts, RHA rats display a more robust sensation/novelty seeking profile, as well as higher baseline levels of impulsivity, and a marked preference for and intake of natural and drug rewards (Zeier et al, 1978; Siegel et al 1993; Escorihuela et al 1999; Giorgi et al 1999; Fernández-Teruel et al 2002). The phenotypic traits that distinguish these lines are at least partly determined by differences in the functional properties of their central dopaminergic pathways: (1) stressors and anxiogenic drugs activate the mesocortical dopaminergic projection of RHA, but not RLA, rats (D'Angio et al, 1988; Corda et al, 1997; Giorgi et al, 2003); (2) RHA rats have a higher density of D-1 dopamine (DA) receptors in the NAc (Giorgi et al, 1994); (3) the acute administration of psychostimulants and morphine causes a larger increment in motor activity and in DA output in the shell than in the core of the NAc of RHA, but not RLA, rats (Lecca et al, 2004); (4) the repeated administration of psychostimulants and morphine induces behavioral sensitization only in RHA rats (Piras et al, 2003; Corda et al, 2005; Giorgi et al, 2005a); (5) in sensitized RHA rats, a subsequent challenge with these drugs elicits a more robust increment in DA output in the NAc-core, associated with an attenuated dopaminergic response in the NAc-shell, whereas these adaptive changes are not observed in sensitization-resistant RLA rats (Giorgi et al, 2005b, 2007).

Collectively, these findings indicate that, compared with their RLA counterparts, RHA rats are more responsive to the acute effects of morphine and psychostimulants and more susceptible to develop behavioral and mesolimbic DA sensitization upon repeated exposure to these substances. Given the postulated role of sensitization in substance use disorders (Robinson and Berridge, 2003), it was considered of interest to evaluate whether RHA rats are also more prone than RLA rats to intravenously self-administer drugs of abuse. To this aim, the acquisition, maintenance and extinction of cocaine self-administration (SA) behavior was assessed in RHA and RLA rats using a continuous (FR-1) reinforcement schedule with lever-pressing as operandum. Next, the propensity of RHA and RLA rats, kept under extinction conditions for 3 weeks, to resume lever-pressing behavior upon the administration of priming doses of cocaine was investigated by means of a between-session model of extinction/reinstatement, as previously described (Fattore et al, 2003). Finally, cocaine was made again contingently available to compare the ability of the two lines to reacquire SA behavior.

\section{MATERIALS AND METHODS}

\section{Animals}

Male Roman high- (RHA) and low-avoidance (RLA) rats weighing 255-278 $\mathrm{g}$ at the beginning of the experiments were bred in the colony established in 1998 at the Department of Toxicology, University of Cagliari, Italy (Giorgi et al, 2007). Animals were acclimated to the housing facilities of the Department of Neuroscience of the same University for at least 10 days before beginning the experiments. They were initially housed in groups of four in a temperature- and humidity-controlled room $\left(21 \pm 1^{\circ} \mathrm{C}\right.$ and $50 \pm 10 \%$, respectively) and under a reversed $12 \mathrm{~h}$ lightdark cycle (light on: $1900 \mathrm{~h}$ ) with tap water available ad libitum. Standard Purina laboratory chow was freely available until operant training started, and it was subsequently delivered once daily after each SA session at $\sim 20$ g/ day, providing to maintain body weight and growth rates. Animals were handled for approximately $10 \mathrm{~min} /$ day for at least 1 week before surgery. Rats were housed individually after surgery to avoid damage to the catheter itself or the surrounding tissues caused by playing, fighting or other kind of interactions with littermates.

All the experiments were carried out during the dark phase of the cycle, five days/week, and were performed in accordance with the guidelines and protocols approved by the European Union (EU Council 86/609; D.L. 27.01.1992, No. 116) and by the Animal Research Ethics Committee of the University of Cagliari.

\section{Intravenous Catheter Implantation}

Animals were anesthetized with an intraperitoneal (i.p.) injection of Equithesin $(5 \mathrm{ml} / \mathrm{kg})$, and implanted with silastic catheters (CamCaths, Cambridge, UK) inserted into the right external jugular vein, as previously described (Fattore et al, 2001). After surgery, each animal received a daily subcutaneous administration of $0.1 \mathrm{ml}$ Baytrill ${ }^{\circledR}$ and was allowed to recover with food and water freely available for a minimum of 6 days. Catheters were flushed daily at the end of the SA session with $0.15 \mathrm{ml}$ of heparinized saline 
solution $(30 \mathrm{U} / \mathrm{ml} 0.9 \%$ sterile saline) to prevent clogging. Catheter patency was verified at the end of the experiments (ie, after the last reacquisition session) by intravenous (i.v.) infusion of the short-acting barbiturate methohexital sodium (Brevital ${ }^{\circledR}, 10 \mathrm{mg} / \mathrm{ml}, 2 \mathrm{mg} / \mathrm{rat}$ ); a positive test was indicated by loss of righting reflex within $5 \mathrm{~s}$ after injection.

\section{Drugs}

For SA training, cocaine hydrochloride (Sigma, Italy) was dissolved in sterile $0.9 \%$ saline solution (volume of injection: $0.1 \mathrm{ml} /$ infusion). To ensure sterility, drug solutions were filtered through $22 \mu \mathrm{m}$ syringe filters prior to use. For reinstatement tests (ie, drug primings), cocaine was dissolved in sterile saline and administered i.p. at a volume of $5 \mathrm{ml} / \mathrm{kg}, 10 \mathrm{~min}$ before starting the reinstatement test session. All antibiotics and anesthetics were purchased as sterile solutions from local suppliers.

\section{Apparatus}

Experiments took place in 10 standard operant conditioning chambers (Med Associates, USA) housed in a soundattenuating box equipped with a ventilating fan and a white noise. Each chamber $(29.5 \times 32.5 \times 23.5 \mathrm{~cm})$ was fitted with two retractable levers positioned $12 \mathrm{~cm}$ apart, each $4 \mathrm{~cm}$ wide, extending $1.5 \mathrm{~cm}$ into the box and situated $8 \mathrm{~cm}$ above the chamber floor. Intravenous infusions of cocaine were delivered from a $5 \mathrm{ml}$ syringe set in a computer-controlled infusion pump (Med Associates, USA) placed outside each chamber, connected to a counterbalanced single-channel swivel and an extra length of plastic tubing enclosed in a metal spring connecting the swivel to the catheter fitting on the animal's back. The entire system was computerintegrated using Med PC for Windows (Med Associates, USA). A white circular cue light $(2.5-\mathrm{W}, 24-\mathrm{V})$ was placed above each lever and a yellow house light $(2.5-\mathrm{W}, 24-\mathrm{V})$ was located on the opposite end of the chamber. Depression of one lever, defined as active, resulted in extinguishing the house light and the illumination of the cue light above the active lever, which remained on for $15 \mathrm{~s}$. Simultaneously, both levers retracted and the infusion pump was activated for $5.8 \mathrm{~s}$, delivering $0.1 \mathrm{ml}$ intravenous infusion of cocaine solution. On completion of the $15 \mathrm{~s}$ time-out period, the levers were re-extended into the chamber, the cue light went out and the house light was illuminated. Depressions on the other lever, defined as inactive, had no programmed consequences but were always recorded, thus providing an index of basal lever-pressing activity. The assignment of the active (drug-paired) and the inactive levers was counterbalanced between RHA and RLA groups and remained constant for each subject throughout the experiment. Cocaine SA occurred under a continuous (FR-1) schedule of reinforcement, that is, each active lever-press was reinforced. Each daily session lasted $3 \mathrm{~h}$.

\section{Experimental Procedures}

Figure 1 provides a schematic representation of the experimental design. Each rat was tested in a series of different phases conducted from Mondays to Fridays within the same test chamber and at the same approximate time of the day (ie, between 1000 and $1430 \mathrm{~h}$ ). The total number of active and inactive lever-presses as well as the temporal patterns of responding were recorded throughout each test session.

Acquisition and maintenance of cocaine self-administration. Cocaine SA testing started 1 week after surgery and was conducted in five daily $3 \mathrm{~h}$ sessions/week over four consecutive weeks. Escalating cocaine doses were available in the first 3 weeks $(0.1,0.2$, and $0.4 \mathrm{mg} / \mathrm{kg} / \mathrm{inf})$, followed by the fourth week in which rats were allowed to stabilize their patterns of responding for cocaine $0.4 \mathrm{mg} / \mathrm{kg} / \mathrm{inf}$. A maximum of 50 cocaine infusions was available in each test session throughout cocaine SA training to prevent overdosing, and sessions were terminated upon reaching this maximum. Acquisition criterion was defined as selfadministering $\geqslant 20$ cocaine injections for three consecutive test sessions.

Extinction of responding. At the end of the 4th week of training, extinction condition was introduced by replacing cocaine with saline, allowing responding to be recorded without drug consequences. All the other experimental parameters were left unchanged, so that pressing on the active lever resulted in an infusion of $0.1 \mathrm{ml}$ of saline accompanied by the presentation of the stimulus light previously paired with cocaine delivery. Drug-reinforced behavior was considered extinguished when the number of active lever-presses was $\leqslant 10$ and the total number of lever responses (ie, active + inactive) in a single test session was $\leqslant 20$.

On alternate days during the last (third) week of extinction, rats received two injections of saline $(5 \mathrm{ml} / \mathrm{kg}$, i.p.) as habituation to subsequent drug priming administrations.

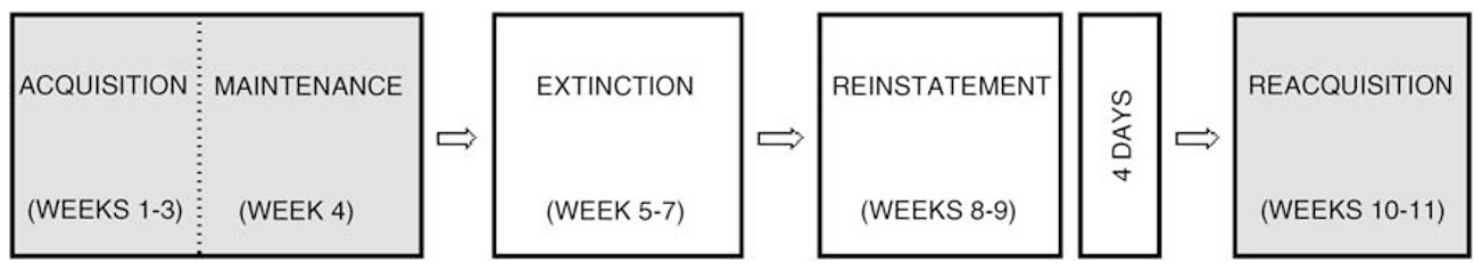

Figure I Schematic representation of the experimental design. Each rectangle denotes a different phase of the study. The gray rectangles denote sessions in which each active lever press was reinforced with cocaine. The infusion doses were $0.1,0.2$, and $0.4 \mathrm{mg} / \mathrm{kg}$ during the first, second, and third week of the acquisition phase, respectively. The infusion dose during the maintenance phase (ie, 4th week) was $0.4 \mathrm{mg} / \mathrm{kg}$. The white rectangles denote sessions under extinction conditions (ie, with saline substituted for cocaine). During drug-induced reinstatement testing (ie, 8th and 9th weeks), four different priming doses of cocaine $(0,2.5,5$, and $10 \mathrm{mg} / \mathrm{kg}$ ) were injected i.p. 10 min before starting the test sessions. The reacquisition phase was started 4 days after the last drug priming injection. The reinforcing cocaine dose throughout the reacquisition phase (ie, IOth and I Ith weeks) was $0.1 \mathrm{mg} / \mathrm{kg}$. 
Drug-induced reinstatement of cocaine-seeking behavior. The effect of non-contingent cocaine priming injections was tested in both groups after 3 weeks of training under extinction conditions, using the 'between-session' reinstatement method (Shalev et al, 2002; Fattore et al, 2003). Training for drug self-administration, extinction of leverpressing activity and reinstatement tests were therefore carried out on different days. Reinstatement tests were conducted under extinction conditions, that is, with each active lever-press delivering saline instead of cocaine. Each rat was given an i.p. priming injection of saline $(2 \mathrm{ml} / \mathrm{kg})$ and three i.p. priming injections of cocaine $(2.5,5.0$ and $10 \mathrm{mg} / \mathrm{kg}$ ), $10 \mathrm{~min}$ before starting the session. Cocaine and saline injections were assigned by means of a Latin Square design. The ability of cocaine to reinstate extinguished drug-seeking behavior was therefore assessed in four test sessions with a 2-day extinction period separating each priming test.

Reacquisition of cocaine self-administration after extinction. Four days after the last drug priming injection, animals were allowed to resume cocaine self-administration at the initial training dose of $0.1 \mathrm{mg} / \mathrm{kg} /$ infusion. Drugtaking behavior was monitored in both RHA and RLA rats over nine consecutive sessions. All the experimental parameters (ie, time-out period, time and volume of drug infusions, light stimuli) were left unchanged.

\section{Data Analyses}

For acquisition and maintenance of cocaine SA, each week of testing at a given infusion dose was assessed by independent analyses of active and inactive lever-pressing activity using two-way analysis of variance (ANOVA) with repeated measures over test session number and animal line (ie, RHA vs RLA) as the main factor. The same procedure was used to analyze extinction from cocaine reinforcement and reacquisition of cocaine SA after extinction. Druginduced reinstatement data were assessed by three-way ANOVA with repeated measures over cocaine dose [main factors: (i) animal line, and (ii) lever (ie, active $v s$ inactive)]. Latency to the first active lever-press following cocaine primings was evaluated by means of two-way ANOVA with repeated measures over cocaine dose and animal line as the main factor. Wherever applicable (ie, when the main effects and/or their interactions were significant), post hoc pairwise contrasts were carried out using the Tukey honest significant difference (HSD) test. The number of test sessions required by each animal line to extinguish lever-pressing behavior was compared with the Mann-Whitney $U$-test.

\section{RESULTS}

\section{Acquisition and Maintenance of Cocaine Self-Administration}

Figure 2 shows responding of RHA and RLA rats on the active lever (upper panel) and inactive lever (lower panel) during the acquisition and maintenance phases of cocaine SA training. The lever-pressing activity values recorded from each animal line in sessions 1 through 20 were binned in 4 weekly blocks (ie, five sessions/block), and the results from each week were evaluated separately by means of a two-way ANOVA for repeated measures over session number. Analysis of the response rates on the active lever showed no significant effects of line or line $\mathrm{X}$ session interaction over the first 2 weeks $(p>0.4)$, whereas in the third and fourth weeks a significantly higher active lever-pressing rate was observed in RHA compared with RLA rats (line: (i) third week, F1, 14 =10.68, $p<0.01$; (ii) fourth week, F1, $14=23.47, p<0.001)$. Moreover, post hoc contrasts revealed significant line-related differences in the rates of active lever-pressing for sessions number 13 and 15 in the 3 rd week and for all the sessions (16-20) of the 4th week (Figure 2, top panels). In contrast, inactive lever-pressing rates of RHA and RLA rats were statistically indistinguishable throughout the 4 weeks (all $p$-values for line and line $\mathrm{X}$ session number interaction $>0.05$; Figure 2, bottom panels). None of the rats of either line met the acquisition criterion (ie, self-administering $\geqslant 20$ cocaine injections for three consecutive test sessions) over the first 2 weeks (top panel), suggesting that RHA rats are not more sensitive than RLA rats to low reinforcing doses $(0.1$ and $0.2 \mathrm{mg} / \mathrm{kg} / \mathrm{inf})$ of cocaine. In contrast, all RHA and RLA rats reached this criterion by the end of the third week $(0.4 \mathrm{mg} / \mathrm{kg} / \mathrm{inf})$ and active lever-pressing activity remained stable and more frequent in RHA rats in all subsequent training sessions. In keeping with these findings, the total amount of cocaine consumed by RHA rats throughout the 20 test sessions $(152.74 \pm 8.54 \mathrm{mg} / \mathrm{kg})$ was significantly larger than the amount consumed by RLA rats $(110.79 \pm 2.72 \mathrm{mg} / \mathrm{kg})$ (one-way ANOVA: F1, $14=21.91, p<0.01$ ).

As shown in Figure 3 (panel a), analysis of temporal patterns of responding revealed quantitative but not qualitative line-related differences during SA training. When animals were given access to cocaine 0.1 or $0.2 \mathrm{mg} / \mathrm{kg} / \mathrm{inf}$, the responding rate of both lines was typically slow and evenly distributed throughout the test session. However, when cocaine was made available at the dose of $0.4 \mathrm{mg} / \mathrm{kg} / \mathrm{inf}$, RHA rats displayed a markedly higher response rate than RLA rats, with both groups selectively increasing responding on the cocaine-paired, but not on the inactive, lever. Notably, only one of eight RHA rats selfadministered the maximum allotted 50 cocaine infusions, thus concluding its test session in less than $3 \mathrm{~h}$, whereas none of the RLA rats was able to self-administer 50 cocaine infusions in any of the 20 test sessions.

\section{Extinction of Responding}

RHA and RLA rats displayed clear cut differences in the time course of operant behavior at the active $v s$ inactive lever when saline was substituted for cocaine (Figure 4). Thus, two-way ANOVA of responding on the active lever showed significant effects of line (F1, $14=10.7 p<0.01)$, session number $(\mathrm{F} 14,196=99.27, p<0.0001)$, and their interaction (F14, 196 =9.10, $p<0.0001)$; moreover, post hoc contrasts revealed that the responding rates were significantly higher in RHA than RLA rats across extinction sessions 1 through 4 (Figure 4, panel a). In contrast, two-way ANOVA of responding on the inactive lever indicated no significant effect of line $(F 1,14=0.0 p=0.93)$ but highly significant effects of session number (F14, 196 $=85.32, p<0.0001)$ and line $\mathrm{X}$ session number interaction (F14, 196 $=5.06$, 


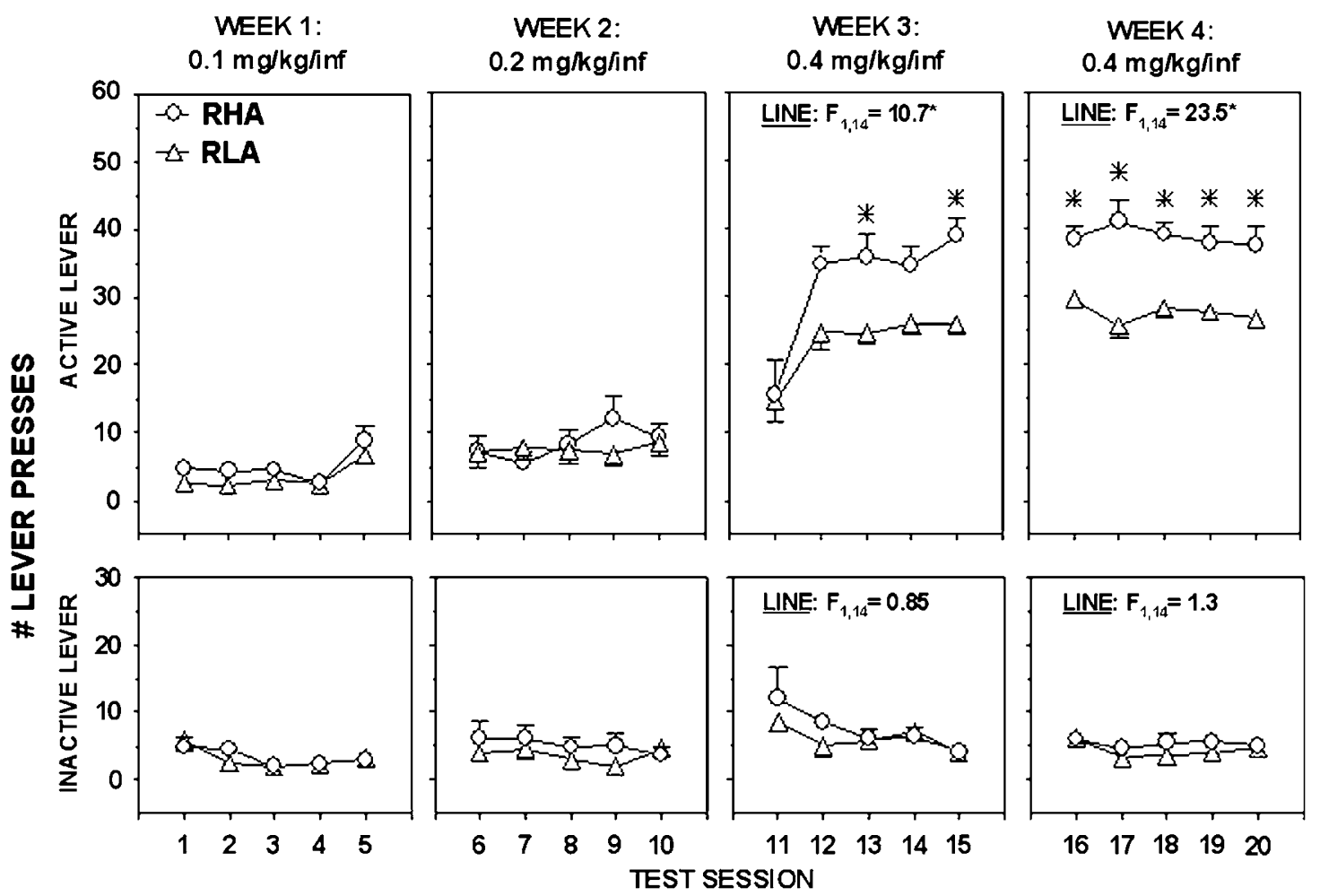

Figure 2 Acquisition and maintenance of cocaine self-administration in RHA (circles) and RLA (triangles) rats. Escalating doses of cocaine (0.I, 0.2, and $0.4 \mathrm{mg} / \mathrm{kg}$ ) were made available over four consecutive weeks. Data are presented as the mean \pm SEM number of active (top) and inactive (bottom) lever presses in each test session ( $n=8$ rats/line). $* p<0.05$ vs the test session-matched active lever responding rate of the RLA line (two-way ANOVA with repeated measures over test session, followed by pairwise contrasts with the HSD Tukey test).

$p<0.0001)$. Furthermore, post hoc contrasts revealed that, in the first extinction session, RLA rats pressed the inactive lever at a significantly higher rate than did their RHA counterparts (Figure 4, panel a; see also temporal response patterns in Figure 3, panel b). Finally, RHA rats were more resistant to extinction than RLA rats (average of seven sessions $v s$ four sessions, respectively; see Figure 4, panel c). Collectively, these findings indicate that, compared with their RLA counterparts, RHA rats retained better ability to discriminate between the two levers and were more persistent in their responses on the active lever during the extinction phase.

\section{Drug-Induced Reinstatement of Cocaine-Seeking Behavior}

Upon achievement of extinction criterion, and 3 weeks after the last cocaine SA session, animals were tested for cocaineinduced reinstatement of drug-seeking behavior (Figure 5).

Following pretreatment with saline, the responding rates of RHA and RLA rats on the active lever were statistically indistinguishable from the average baseline lever-pressing rates displayed in the last three extinction test sessions (ie, sessions nos. 13-15; compare Figures 4 and 5). In contrast, both lines increased in a dose-dependent manner their response rates on the active lever following priming cocaine injections, although this effect was more robust in RHA than RLA rats (three-way ANOVA with repeated measures over cocaine dose: line, F1, $14=189.65, p<0.001$; lever, $\mathrm{F} 1$,
$14=784.47, p<0.001$; dose, F3, $42=217.99, p<0.001$; line $\mathrm{X}$ lever X dose, F3, $42=26.86, p<0.01$ ). Notably, pairwise post hoc contrasts showed that, when primed with the lowest dose of cocaine $(2.5 \mathrm{mg} / \mathrm{kg})$, only RHA reinstated operant responding on the lever previously paired with the drug (Figure 5, top panel). Moreover, with higher cocaine doses $(5$ and $10 \mathrm{mg} / \mathrm{kg})$, the increment in the rate of active lever-pressing was greater in RHA rats than in their RLA counterparts. It is noteworthy that, in RHA rats, the effect of $5 \mathrm{mg} / \mathrm{kg}$ of cocaine was already maximum, while in RLA rats the increment in the rate of lever-pressing was greater after $10 \mathrm{mg} / \mathrm{kg}$ of cocaine as compared with the $5 \mathrm{mg} / \mathrm{kg}$ dose. Representative temporal response patterns of cocaine-induced reinstatement are shown in Figure 3 (panel c).

As shown in Figure 6, assessment of the mean latencies to the first active lever-press using two-way ANOVA revealed additional line-related differences in the responsiveness to priming doses of cocaine (line: $\mathrm{F} 1,14=90.5$; dose: $\mathrm{F} 3$, $42=369.2$; line $\times$ dose: $\mathrm{F} 3,42=74.2$; all $p$-values $<0.0001$ ). Although both lines showed similar latencies after the injection of saline, the onset of active lever-pressing following a cocaine dose of $2.5 \mathrm{mg} / \mathrm{kg}$ was significantly faster in RHA than RLA rats, whereas no line related differences were observed with higher doses of cocaine. Notably, also the mean latency times over the last three sessions of SA training (ie, nos. 18-20), were significantly shorter in RHA than RLA rats (two-tailed Student's $t$ test: $t_{14}, 8.76, p<0.001$; see Figure 6, left side). 


\section{RHA}

RLA

\section{a Acquisition and maintenance}

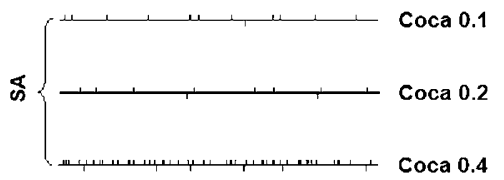

b Extinction<smiles>[10BH]</smiles>

畜 \{

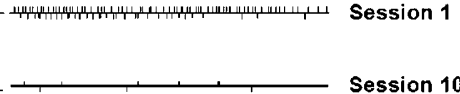

C Drug-induced reinstatement

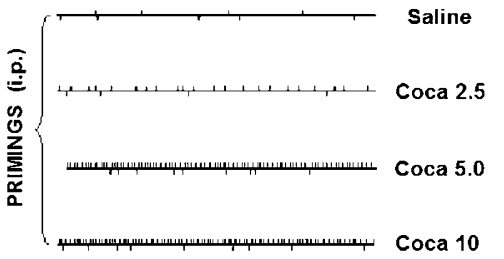

d Reacquisition

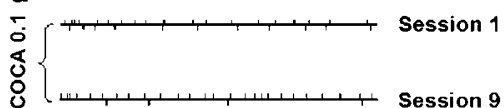

Figure 3 Individual representative records illustrating responding patterns of RHA (left) and RLA (right) rats at the active (upward ticks) and inactive (downward ticks) lever in $3 \mathrm{~h}$ test sessions throughout the four phases of the study. Each tick denotes the time of every response on the active or inactive lever. (a) Acquisition and maintenance of cocaine (Coca) self-administration (SA) with escalating reinforcing doses of the drug (mg/kg/inf): 0.1 (top trace), 0.2 (middle trace) and 0.4 (bottom trace). (b) Extinction (EXT) of lever-pressing activity. Top trace, Ist EXT session; bottom trace, last (I Oth) EXT session. (c) Reinstatement of lever-pressing activity induced by priming doses of cocaine [0 (saline); 2.5; 5; 10; $\mathrm{mg} / \mathrm{kg}$, i.p.]. (d) Reacquisition of lever-pressing activity with contingently available cocaine $(0.1 \mathrm{mg} / \mathrm{kg} / \mathrm{inf})$. Top trace, Ist reacquisition session; bottom trace, last (9th) reacquisition session.

\section{Reacquisition of Cocaine Self-Administration after Extinction}

The final phase of the study was preceded by a 4-day extinction period, starting immediately after the last drug priming injection, and consisted of nine test sessions. As illustrated in Figure 7, when cocaine was available at a dose as low as $0.1 \mathrm{mg} / \mathrm{kg} / \mathrm{inf}$ (which, as shown in Figure 2, failed to serve as a positive reinforcer in drug-naive animals), cocaine SA was promptly reacquired by RHA, but not RLA, rats. Thus, evaluation of responding rates by means of twoway ANOVA revealed a significant effect of line for the active lever (F1, $14=15.01, p<0.01)$, but not for the inactive lever $(\mathrm{F} 1,14=0.12, p>0.7)$. Moreover, within the RHA line, the mean number of active lever-presses across the nine reacquisition sessions $(20.01 \pm 3.62)$ was significantly greater than the mean number of lever presses recorded during the first $(5.05 \pm 0.48)$ and second $(8.52 \pm 1.71)$ training weeks, when cocaine was contingently available at unitary doses of $0.1 \mathrm{mg} / \mathrm{kg} / \mathrm{inf}$ and $0.2 \mathrm{mg} / \mathrm{kg} / \mathrm{inf}$, respectively (oneway ANOVA: F2, $21=11.31$, followed by pairwise contrasts with the HSD Tukey test, $p<0.05$ ).

Finally, analysis of the response patterns during the $3 \mathrm{~h}$ SA sessions confirmed that RHA rats rapidly recovered the
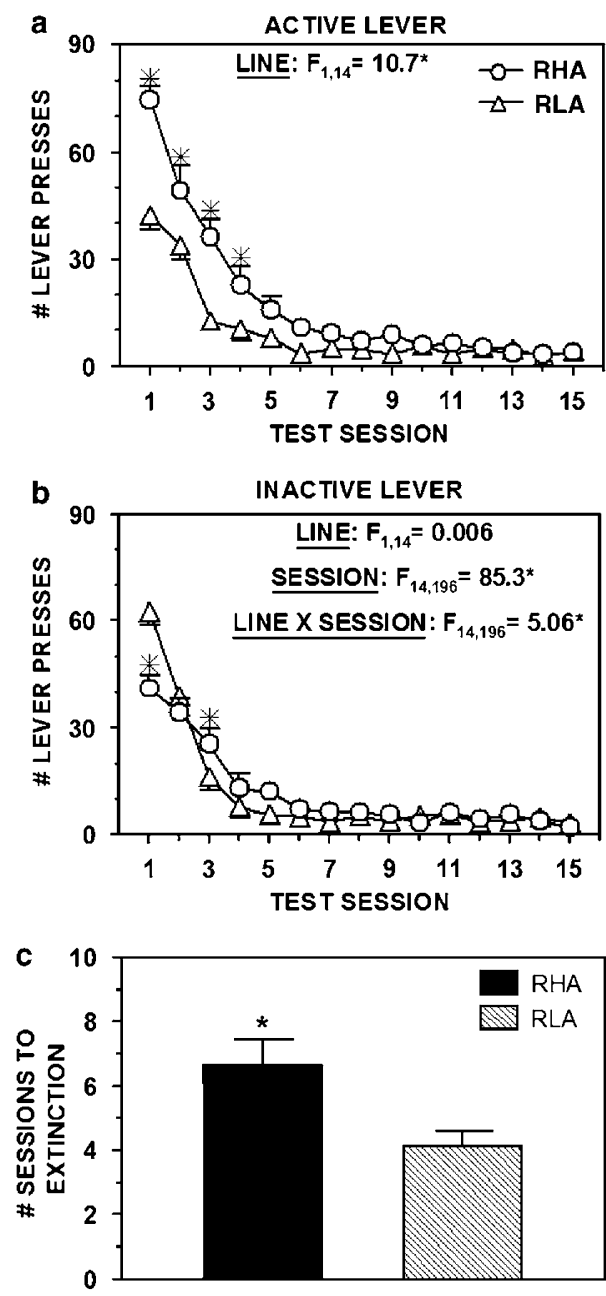

Figure 4 Extinction of cocaine-reinforced operant behavior in RHA (circles) and RLA (triangles) rats. Saline was substituted for cocaine over three consecutive weeks. Data are presented as the mean \pm SEM number of active (panel a) and inactive (panel b) lever presses in each extinction test session ( $n=8$ rats/line). $* p<0.05$ vs the lever type- and test sessionmatched responding rate of the RLA line (two-way ANOVA with repeated measures over test session, followed by pairwise contrasts with the HSD Tukey test). Panel c: Latency to extinction of RHA (solid bars) and RLA (striped bars) rats. Data are presented as the mean \pm SEM number of sessions needed to meet the extinction criteria [ie, number of active lever presses $\leqslant 10$ and total number of lever responses (active + inactive) in a single test session $\leqslant 20 ; n=8$ rats/line] ${ }^{*} p<0.05$ vs the RLA line (Mann-Whitney U-test).

ability to discriminate between the two levers and maintained significantly higher rates of responding as long as cocaine was available, whereas RLA rats showed fewer sparsely distributed responses, with no differences in the mean number of responses made on the active and inactive levers (Figure 3, panel d).

\section{DISCUSSION}

The present results demonstrate that the Roman lines differ in the propensity to intravenously self-administer cocaine. Thus, compared with their RLA counterparts, RHA rats show higher rates of responding during acquisition, 


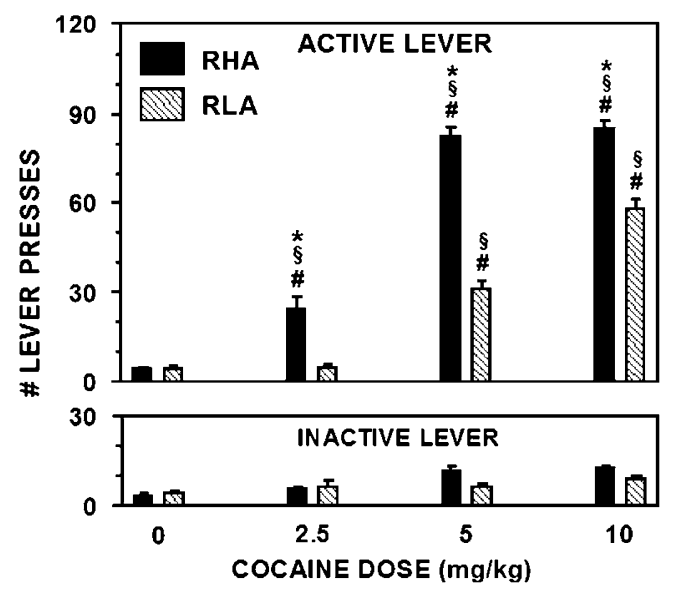

Figure 5 Cocaine-induced reinstatement of drug-seeking behavior in RHA (solid bars) and RLA (striped bars) rats kept under extinction conditions for 3 weeks. Data are presented as the mean \pm SEM number of active (top) and inactive (bottom) lever presses following an acute priming dose of cocaine [0 (saline); $2.5 ; 5 ; 10 ; \mathrm{mg} / \mathrm{kg}$, i.p.; $n=8$ rats/line]. $* p<0.05$ vs the dose-matched RLA value; ${ }^{\S} p<0.05$ vs the line- and dose-matched inactive lever value; ${ }^{\#} p<0.05$ vs the line-matched saline value (three-way ANOVA with repeated measures over cocaine dose, followed by pairwise contrasts with the HSD Tukey test).

maintenance, extinction, and drug-induced reinstatement of cocaine SA. Moreover, following prolonged abstinence, RHA, but not RLA, rats reacquire cocaine SA with a reinforcing unit dose as low as $0.1 \mathrm{mg} / \mathrm{kg}$, which is not reinforcing in drug-naive animals.

The reinforcing properties of cocaine, one of the most addictive substances known to date, are believed to result from its ability to inhibit the reuptake of biogenic amines, which in turn potentiates dopamine neurotransmission in limbic and cortical circuits (Pierce and Kumaresan, 2005). Cocaine is readily self-administered by laboratory animals, and the rate of responding is critically dependent on a variety of experimental conditions, including drug unitary dose, session length, number of training sessions, and reinforcement schedule (Koob and Le Moal, 2006). In this study, animals were trained to self-administer cocaine using ascending doses of the drug and an FR1 reinforcement schedule, since this experimental design has been shown to induce robust cocaine $\mathrm{SA}$ in other rat strains (Chambers and Self, 2002).

Although both lines needed a similar number of training sessions to acquire SA behavior, the lever-pressing rate during the maintenance sessions was remarkably higher in RHA than RLA rats. As a result, the total amount of cocaine consumed by RHA rats over the 20 test sessions ( $\cong 150 \mathrm{mg} / \mathrm{kg}$ ) was significantly larger than that consumed by RLA rats ( $\cong 110 \mathrm{mg} / \mathrm{kg})$. Thus, RHA rats appear to be more responsive than RLA rats to the reinforcing effects of cocaine, in keeping with the notion that these lines differ in the behavioral and neurochemical responses to the acute and repeated exposure to a variety of addictive drugs, including ethanol, morphine and psychostimulants (Fernández-Teruel et al, 2002; Lecca et al, 2004; Giorgi et al, 2007).

Line-related differences in the responding rates on the active lever were also observed when saline was substituted for cocaine: thus, RHA rats needed more sessions than

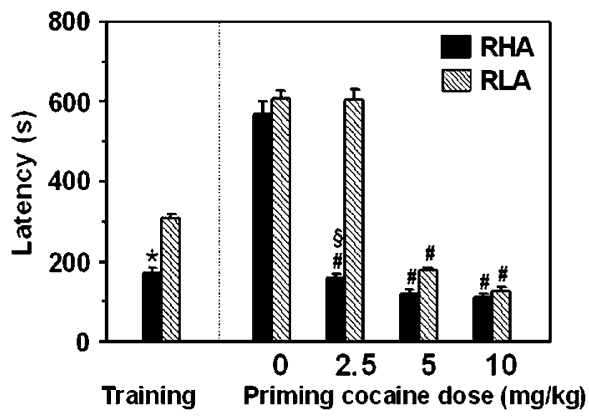

Figure 6 Latency to the first response on the active lever following primings with saline or cocaine. Data are presented as the mean \pm SEM time (s) taken to make the first active lever press of RHA (solid bars) and RLA (striped bars) rats. For comparison, the average latency over the last three sessions (ie, nos. 18-20) of SA training before extinction is indicated on the left side of the figure. ${ }^{*} p<0.00$ I vs the session-matched RLA value (2-tailed Student's $t$ test); ${ }^{{ }} p<0.05$ vs the cocaine dose-matched RLA value; $\# p<0.05$ vs the line-matched mean latency after saline injection (two-way ANOVA with repeated measures over cocaine dose, followed by pairwise contrasts with the HSD Tukey test).

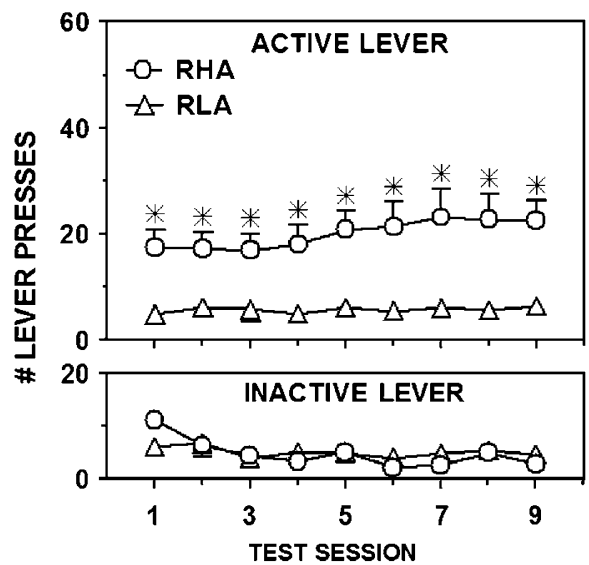

Figure 7 Reacquisition of cocaine self-administration in RHA (circles) and RLA (triangles) rats. Cocaine $(0.1 \mathrm{mg} / \mathrm{kg} / \mathrm{inf})$ was made contingently available over nine consecutive test sessions. Data are presented as the mean \pm SEM number of active (top) and inactive (bottom) lever presses in each test session ( $n=8$ rats/line). ${ }^{*} p<0.05$ vs the test session-matched active lever responding rate of the RLA line (two-way ANOVA with repeated measures over test session, followed by pairwise contrasts with the HSD Tukey test).

RLA rats to extinguish operant responding. Moreover, while RHA rats persisted in responding on the active lever, suggesting that they retained the ability to discriminate the lever previously paired with cocaine along the extinction test sessions, RLA rats tended to press more frequently the inactive lever, especially during the initial extinction sessions.

It has been posited that extinction paradigms provide reliable measures of the rewarding/motivational properties of psychoactive substances by assessing the perseverance in drug-seeking behavior in the absence of responsecontingent drug availability (Markou et al, 1993). Because the rate of responding of RHA rats was consistently higher than that of RLA rats not only when cocaine was contingently available during the acquisition and maintenance 
sessions, but also in its absence during the extinction sessions, it may be proposed that the RHA line has a higher propensity to acquire and retain cocaine-seeking behavior. In keeping with this hypothesis, reinstatement of drugseeking behavior following non-contingent cocaine injections was more robust in RHA than RLA rats. Intriguingly, previous studies on ethanol and saccharin intake using a two-bottle free choice paradigm have shown that, compared with RLA rats, RHA rats display a higher preference for both ethanol and saccharin solutions over water (Razafimanalina et al, 1996; Fernández-Teruel et al, 2002). These findings suggest that the line-related differences in the responsiveness to cocaine SA observed in the present study may also extend to the voluntary intake of other drugs of abuse or natural reinforcers, although further studies are required to establish whether the line-related behavioral differences reported herein indeed reflect a higher motivation for cocaine in RHA vs RLA rats.

Another neurobiological mechanism that may contribute to the resilience of RHA rats to extinguish operant responding is a dysfunction of the frontocortical neuronal circuits that are critically involved in the inhibition of ongoing activity upon withdrawal of the reinforcers (Jentsch and Taylor, 1999). Thus, it has been hypothesized that long-term exposure to drugs of abuse may alter the functional activity of dopaminergic afferent projections and glutamatergic neurons in frontocortical areas, with a consequent deficiency in the ability to inhibit inappropriate responses to drugs or drug-paired stimuli (Jentsch and Taylor, 1999; Everitt and Wolf, 2002; Chambers et al, 2003; Kalivas et al, 2005; Vanderschuren and Everitt, 2005). It is therefore noteworthy in this context that, compared with RLA rats, the mesocortical dopaminergic system of RHA rats is more robustly activated by both stressful and rewarding stimuli (D'Angio et al, 1988; Corda et al, 1997; Giorgi et al, 1999, 2003). In addition, RHA rats display higher scores than RLA rats in experimental paradigms used to assess sensation/ novelty seeking behavior in rodents (Siegel et al, 1993; Escorihuela et al, 1999; Fernández-Teruel et al, 2002; Steimer and Driscoll 2005). There is also evidence that, compared with RLA rats, RHA rats are less capable of inhibiting non relevant activity, as indicated by a lower efficiency in the acquisition of DRL-20 operant conditioning behavior (Zeier et al, 1978). More recent studies support the view that RHA rats have higher baseline levels of impulsivity than RLA rats: (i) in a delay discounting task, RHA rats made significantly fewer choices of a larger reward when the delay was increased from 0 to 20 or $40 \mathrm{~s}$; (ii) in the 5-choice serial reaction time task, RHA rats made more premature responses (M.J. Gómez Ramirez et al, in preparation).

In human drug users, re-exposure to a drug, or to drugassociated stimuli, often intensifies craving and precipitates relapse, even after long periods of abstinence (Gawin and Kleber, 1986; O’Brien, 1997). Drug-induced reinstatement of extinguished drug-seeking behavior is a model widely used to investigate the neurobiological mechanisms involved in drug-seeking and relapse (de Wit and Stewart, 1981; Markou et al, 1993; Shalev et al, 2002), although its construct validity has not yet been established (Epstein et al, 2006). Previous studies have shown that the ability of priming doses of cocaine, or drug-related cues, to reinstate drug-seeking behavior progressively increases during abstinence, as reflected by significantly higher operant responding rates after long-term (ie, 1-3 months) compared with short-term (ie, 1 day) withdrawal periods (Tran-Nguyen et al, 1998; Grimm et al, 2001). Therefore, in the present study, cocaine-induced reinstatement tests in RHA and RLA rats were started after a 3 -week extinction period, and the priming doses used $(2.5,5$, and $10 \mathrm{mg} / \mathrm{kg}$, i.p.) were within the effective dose range reported in previous cocaineinduced reinstatement studies (Lu et al, 2004). Notably, the lowest dose of cocaine effectively reinstated lever-pressing after long-term extinction only in RHA rats. On the other hand, cocaine-priming doses of 5 and $10 \mathrm{mg} / \mathrm{kg}$ reinstated operant responding in both lines, although the leverpressing rates were significantly higher in RHA rats. In both lines, cocaine-induced reinstatement of operant responding was specific for the lever previously paired with the drug, suggesting that the enhanced responding of RHA rats may be considered as a measure of drug-seeking behavior reflecting incentive motivation, rather than as a non-specific consequence of the general arousal and increased motor activity induced by cocaine. It remains unclear, however, whether the higher lever-pressing rate of RHA rats during the acquisition/maintenance phase may have affected the responding rate in the subsequent reinstatement tests. In this regard, it has been reported that responding rates during drug SA training are not correlated with the intensity of drug-seeking behavior reinstated by priming doses of cocaine following extinction (Leri and Stewart, 2001), although another study has shown a positive association between the level of cocaine intake during prior SA and drug-induced reinstatement of extinguished cocaine-seeking behavior (Sutton et al, 2000).

The Roman lines also differed significantly in the propensity to reacquire SA behavior when a low unitary dose of cocaine $(0.1 \mathrm{mg} / \mathrm{kg} / \mathrm{inf})$ was contingently available, as only RHA rats showed a rapid and stable reacquisition of contingent responding on the active lever. Importantly, the response rate of RHA rats in these sessions was higher than that measured in both the $1 \mathrm{st}(0.1 \mathrm{mg} / \mathrm{kg} / \mathrm{inf})$ and the $2 \mathrm{nd}(0.2 \mathrm{mg} / \mathrm{kg} / \mathrm{inf})$ week of SA training. This effect is reminiscent of the behavioral sensitization observed in rats chronically treated with cocaine.

It is well known that the repeated, non-contingent administration of psychostimulants to rodents induces sensitization of their locomotor stimulating effects (Vanderschuren and Kalivas 2000; Vezina, 2004). This enhanced behavioral response peaks at time points that are well beyond the acute withdrawal phase and persists for months in abstinent rats (Vanderschuren and Kalivas 2000; Li et al, 2004; Giorgi et al, 2007). The repeated exposure to psychostimulants (either contingent or non-contingent) may also lead to the development of sensitization to their incentive-motivational effects (Horger et al, 1990; Piazza et al, 1990; Robinson and Berridge, 2003; Vanderschuren and Everitt, 2005; Morgan et al, 2006). In line with the above studies, the ability of priming doses of cocaine, and of cocaine-paired cues, to reinstate extinguished drug-seeking behavior develops with a time course that is very similar to that of the locomotor sensitization induced by the repeated administration of psychostimulants, suggesting that both phenomena may share the same neural substrates 
(De Vries et al, 1998; Grimm et al, 2001; Zapata et al, 2003; Lu et al, 2004). The experimental design of the present study does not allow us to discern whether or not the repeated exposure to cocaine elicited behavioral (locomotor) sensitization; however, previous studies have consistently shown that only RHA rats display sensitized locomotor responses following repeated, non-contingent treatments with psychostimulants, such as amphetamine (Corda et al, 2005) and cocaine (Giorgi et al, 2005a).

Long-lasting structural and functional changes in the mesocortical/mesolimbic dopaminergic system as well as in its afferent and efferent connections in the mPFC and amygdala are considered to play a central role in the development and persistent nature of psychostimulant sensitization (Tran-Nguyen et al, 1998; Vanderschuren and Kalivas, 2000; Nestler, 2001; Robinson and Berridge, 2003; Li et al, 2004; Vezina, 2004; Ferrario et al, 2005). Accordingly, we have shown that, in RHA rats sensitized to cocaine, the increment in dopamine efflux elicited by the administration of a cocaine challenge after 1 week of abstinence is potentiated in the NAc-core and concomitantly attenuated in the NAc-shell, whereas such adaptive changes are not observed in sensitization-resistant RLA rats (Giorgi et al, 2007). Importantly, the NAc-core has been implicated in the reinstatement of cocaine-seeking induced by the administration of a priming dose of the drug or by exposure to drug-related cues (Ito et al, 2004; Hollander and Carelli, 2007). These findings support the view that the NAc-core and its afferent glutamatergic projections originating in the $\mathrm{mPFC}$ play a key role in cocaine-induced relapse (McFarland et al, 2003). Therefore, future studies in our laboratory will be aimed at clarifying whether longlasting changes in NAc-core and $\mathrm{mPFC}$ function are also implicated in the increased responding rates of RHA vs RLA rats during reinstatement and reacquisition of cocaine SA.

A variety of factors, including individual differences in genetic make up, neuronal circuits, temperament, and social environment, are involved in the transition from casual, controlled, and recreational drug use to the compulsive, uncontrolled, drug use that occurs in approximately $15-20 \%$ of the individuals exposed to addictive substances (Anthony et al, 1994). Hence, an important goal of drug addiction research is to characterize how these factors, and their reciprocal interactions, contribute to the individual vulnerability to substance use disorders.

The selective breeding of RHA and RLA rats for, respectively, rapid $v s$ poor acquisition of two-way active avoidance in the shuttle-box has generated two well characterized phenotypes that differ drastically in several traits, including: (1) functional properties of the mesocortical and mesolimbic dopaminergic projections, (2) temperament traits related to the behavioral spectra of novelty/sensationseeking and impulsivity, and (3) susceptibility to the acute and chronic effects of addictive drugs, including ethanol, morphine, and psychostimulants (for reviews, see Fernández-Teruel et al, 2002; Steimer and Driscoll, 2005; Giorgi et al, 2007). Such distinctive traits of the RHA phenotype may contribute to the increased susceptibility to self-administer contingently available cocaine and to reinstate extinguished operant responding when primed with the same substance. It will be therefore worthwhile to compare the performance of the Roman lines in SA paradigms that distinguish mere drug-taking from the compulsive and uncontrolled drug use that characterize addiction in humans (Robinson 2004; Deroche-Gamonet et al, 2004; Vanderschuren and Everitt 2004). Such studies may eventually clarify whether RHA and RLA rats represent a pair of phenotypes respectively vulnerable and resistant to drug addiction, thus providing a useful experimental model to characterize the relationships among genetic make up, temperament traits and neurobiological mechanisms involved in the individual vulnerability to undergo a transition from drug use to drug addiction.

\section{ACKNOWLEDGEMENTS}

We thank Professor Walter Fratta for thoughtful discussions pertaining to this study and the Reviewers for their useful comments. We thank Ms Barbara Tuveri for her excellent technical assistance. This project was supported by funds from Ministero dell'Università e della Ricerca to MGC and $O G$

\section{DISCLOSURE/CONFLICT OF INTEREST}

The authors declare no conflict of interest.

\section{REFERENCES}

American Psychiatric Association (1994). Diagnostic and Statistical Manual of Mental Disorders, 4th edn, American Psychiatric Association Press: Washington, DC, pp 175-272.

Anthony JC, Warner LA, Kessler RC (1994). Comparative epidemiology of dependence on tobacco, alcohol, controlled substances, and inhalants : Basic findings from the National Comorbidity Survey. Exp Clin Psychopharmacol 2: 244-268.

Bardo MT, Donohew RL, Harrington NG (1996). Psychobiology of novelty seeking and drug seeking behavior. Behav Brain Res 77: 23-43.

Broadhurst PL, Bignami G (1965). Correlative effects of psychogenetic selection: A study of the Roman high and low avoidance strains of rats. Behav Res Ther 3: 273-280.

Chambers RA, Self DW (2002). Motivational responses to natural and drug rewards in rats with neonatal ventral hippocampal lesions: an animal model of dual diagnosis schizophrenia. Neuropsychopharmacology 27: 889-905.

Chambers RA, Taylor JR, Potenza MN (2003). Developmental neurocircuitry of motivation in adolescence: a critical period of addiction vulnerability. Am J Psychiatry 160: 1041-1052.

Corda MG, Lecca D, Piras G, Di Chiara G, Giorgi O (1997). Biochemical parameters of dopaminergic and GABAergic neurotransmission in the CNS of Roman high-avoidance and Roman low-avoidance rats. Behav Genet 27: 527-536.

Corda MG, Piras G., Lecca D, Fernández-Teruel A, Driscoll P, Giorgi O (2005). The psychogenetically selected Roman rat lines differ in the susceptibility to develop amphetamine sensitization. Behav Brain Res 157: 147-156.

Crabbe JC (2002). Genetic contributions to addiction. Annu Rev Psychol 53: 435-462.

D'Angio M, Serrano A, Driscoll P, Scatton B (1988). Stressful environmental stimuli increase extracellular DOPAC levels in the prefrontal cortex of hypoemotional (Roman high-avoidance) but not hyperemotional (Roman low-avoidance) rats. An in vivo voltammetric study. Brain Res 451: 237-247.

De Vries TJ, Schoffelmeer AN, Binnekade R, Mulder AH, Vanderschuren LJ (1998). Drug-induced reinstatement of 
heroin- and cocaine-seeking behaviour following long-term extinction is associated with expression of behavioural sensitization. Eur J Neurosci 10: 3565-3571.

de Wit H, Stewart J (1981). Reinstatement of cocaine-reinforced responding in the rat. Psychopharmacology 75: 134-143.

Deiana S, Fattore L, Spano MS, Cossu G, Porcu E, Fadda P et al. (2007). Strain and schedule-dependent differences in the acquisition, maintenance and extinction of intravenous cannabinoid self-administration in rats. Neuropharmacology 52: 646-654..

Deroche-Gamonet V, Belin D, Piazza PV (2004). Evidence for addiction-like behavior in the rat. Science 305: 1014-1017.

Di Chiara G, Imperato A (1988). Drugs abused by humans preferentially increase synaptic dopamine concentrations in the mesolimbic system of freely moving rats. Proc Natl Acad Sci USA 85: 5274-5278.

Driscoll P, Bättig K (1982). Behavioral, emotional and neurochemical profiles of rats selected for extreme differences in active, two-way avoidance performance. In: Lieblich I (ed). Genetics of the Brain. Elsevier: Amsterdam. pp 95-123.

Ebstein RP, Benjamin J, Belmaker RH (2000). Personality and polymorphisms of genes involved in aminergic neurotransmission. Eur J Pharmacol 410: 205-214.

Epstein DH, Preston KL, Steward J, Shaham Y (2006). Toward a model of drug relapse: an assessment of the validity of the reinstatement procedure. Psychopharmacol 189: 1-16.

Escorihuela RM, Fernández-Teruel A, Gil L, Aguilar R, Tobeña A, Driscoll P (1999). Inbred Roman high- and low-avoidance rats: differences in anxiety, novelty-seeking, and shuttlebox behaviors. Physiol Behav 67: 19-26.

Everitt BJ, Wolf ME (2002). Psychomotor stimulant addiction: a neural systems perspective. J Neurosci 22: 3312-3320.

Fattore L, Cossu G, Martellotta CM, Fratta W (2001). Intravenous self-administration of the cannabinoid CB1 receptor agonist WIN 55, 212-2 in rats. Psychopharmacology 156: 410-416.

Fattore L, Spano MS, Cossu G, Deiana S, Fratta W (2003). Cannabinoid mechanism in reinstatement of heroin-seeking after a long period of abstinence in rats. Eur J Neurosci 17: 1723-1726.

Fernández-Teruel A, Driscoll P, Gil L, Aguilar R, Tobeña A, Escorihuela RM (2002). Enduring effects of environmental enrichment on novelty seeking, saccharin and ethanol intake in two rat lines (RHA/Verh and RLA/Verh) differing in incentiveseeking behavior. Pharmacol Biochem Behav 73: 225-231.

Ferrario CR, Gorny G, Crombag HS, Li Y, Kolb B, Robinson TE (2005). Neural and behavioral plasticity associated with the transition from controlled to escalated cocaine use. Biol Psychiatry 58: 751-759.

Gawin FH, Kleber HD (1986). Abstinence symptomatology and psychiatric diagnosis in cocaine abusers. Clinical observations. Arch Gen Psychiatry 43: 107-113.

Giorgi O, Lecca D, Piras G, Driscoll P, Corda MG (2003). Dissociation between mesocortical dopamine release and fearrelated behaviours in two psychogenetically selected lines of rats that differ in coping strategies to aversive conditions. Eur $J$ Neurosci 17: 2716-2726.

Giorgi O, Orlandi M, Escorihuela RM, Driscoll P, Lecca D, Corda MG (1994). GABAergic and dopaminergic transmission in the brain of Roman high-avoidance and Roman low-avoidance rats. Brain Res 638: 133-138.

Giorgi O, Piras G, Corda MG (2007). The psychogenetically selected Roman high- and low-avoidance rat lines: a model to study the individual vulnerability to drug addiction. Neurosci Biobehav Rev 31: 148-163.

Giorgi O, Piras G, Lecca D, Corda MG (2005a). Behavioural effects of acute and repeated cocaine treatments: a comparative study in sensitisation-prone RHA rats and their sensitisation-resistant RLA counterparts. Psychopharmacology 180: 530-538.
Giorgi O, Piras G, Lecca D, Corda MG (2005b). Differential activation of dopamine release in the nucleus accumbens core and shell after acute or repeated amphetamine injections: a comparative study in the Roman high- and low-avoidance rat lines. Neuroscience 135: 987-998.

Giorgi O, Valentini V, Piras G, Di Chiara G, Corda MG (1999). Palatable food differentially activates dopaminergic function in the CNS of Roman/Verh lines and strains of rats. Soc Neurosci Meeting Abs Book 25: 2152.

Grimm JW, Hope BT, Wise RA, Shaham Y (2001). Neuroadaptation. Incubation of cocaine craving after withdrawal. Nature 412 141-142.

Helmus TC, Downey KK, Arfken CL, Henderson MJ, Schuster CR (2001). Novelty seeking as a predictor of treatment retention for heroin dependent cocaine users. Drug Alcohol Dependence 61: 287-295.

Hollander JA, Carelli RM (2007). Cocaine-associated stimuli increase cocaine seeking and activate accumbens core neurons after abstinence. J Neurosci 27: 3535-3539.

Horger BA, Shelton K, Schenk S (1990). Preexposure sensitizes rats to the rewarding effects of cocaine. Pharmacol Biochem Behav 37: 707-711.

Ito R, Robbins TW, Everitt BJ (2004). Differential control over cocaine seeking behavior by nucleus accumbens core and shell. Nature Neurosci 7: 389-397.

Jentsch JD, Taylor JR (1999). Impulsivity resulting from frontostriatal dysfunction in drug abuse: implications for the control of behavior by reward-related stimuli. Psychopharmacology 146: 373-390.

Kalivas PW, Volkow ND (2005). The neural basis of addiction: a pathology of motivation and choice. Am J Psychiatry 162: 1403-1413.

Kalivas PW, Volkow ND, Seamans J (2005). Unmanageable motivation in addiction: a pathology in prefrontal-accumbens glutamate transmission. Neuron 45: 647-650.

Koob GF, Ahmed SH, Boutrel B, Chen SA, Kenny PJ, Markou A et al. (2004). Neurobiological mechanisms in the transition from drug use to drug dependence. Neurosci Biobehav Rev 27: 739-749.

Koob GF, Le Moal M (2006). : Psychostimulants. In: Neurobiology of Addiction. Elsevier: Amsterdam. pp 69-120.

Kosten TA, Miserendino MJ, Haile CN, DeCaprio JL, Jatlow PI, Nestler EJ (1997). Acquisition and maintenance of intravenous cocaine self-administration in Lewis and Fischer inbred rat strains. Brain Res 778: 418-429.

Laakso A, Mohn AR, Gainetdinov RR, Caron MG (2002). Experimental genetic approaches to addiction. Neuron 36: 213-228.

Lecca D, Piras G, Driscoll P, Giorgi O, Corda MG (2004). A differential activation of dopamine output in the shell and core of the nucleus accumbens is associated with the motor responses to addictive drugs: a brain dialysis study in Roman high- and low-avoidance rats. Neuropharmacology 46: 688-699.

Leri F, Stewart J (2001). Drug-induced reinstatement to heroin and cocaine seeking: a rodent model of relapse in poly-drug use. Exp Clin Psychopharmacol 9: 297-306.

Li Y, Acerbo MJ, Robinson TE (2004). The induction of behavioural sensitization is associated with cocaine-induced structural plasticity in the core (but not shell) of the nucleus accumbens. Eur J Neurosci 20: 1647-1654.

Lu L, Grimm JW, Dempsey J, Shaham Y (2004). Cocaine seeking over extended withdrawal periods in rats: different time courses of responding induced by cocaine cues versus cocaine priming over the first 6 months. Psychopharmacology 176: 101-108.

Markou A, Weiss F, Gold LH, Caine SB, Schulteis G, Koob GF (1993). Animal models of drug craving. Psychopharmacology 112: $163-182$.

McClung CA, Nestler EJ (2003). Nat Neurosci 6: 1208-1215. 
McFarland K, Lapish CC, Kalivas PW (2003). Prefrontal glutamate release into the core of the nucleus accumbens mediates cocaineinduced reinstatement of drug-seeking behavior. J Neurosci 23: 3531-3537.

McLellan AT, Lewis DC, O'Brien CP, Kleber HD (2000). Drug dependence, a chronic medical illness: implications for treatment, insurance, and outcomes evaluation. JAMA 284: 1689-1695.

Morgan D, Liu Y, Roberts DC (2006). Rapid and persistent sensitization to the reinforcing effects of cocaine. Neuropsychopharmacology 31: 121-128.

Nestler EJ (2001). Molecular basis of long-term plasticity underlying addiction. Nat Rev Neurosci 2: 119-128.

O'Brien CP (1997). A range of research-based pharmacotherapies for addiction. Science 278: 66-70.

Piazza PV, Deminiere JM, le Moal M, Simon H (1990). Stress- and pharmacologically-induced behavioral sensitization increases vulnerability to acquisition of amphetamine self-administration. Brain Res 514: 22-26.

Pierce RC, Kumaresan V (2005). The mesolimbic dopamine system: the final common pathway for the reinforcing effect of drugs of abuse? Neurosci Biobehav Rev 30: 215-238.

Piras G, Lecca D, Corda MG, Giorgi O (2003). Repeated morphine injections induce behavioral sensitization in Roman high- but not in Roman low-avoidance rats. Neuroreport 14: 2433-2438.

Razafimanalina R, Mormède P, Velley L (1996). Gustatory preference-aversion profiles for saccarine, quintine and alcohol in Roman high- and low-avoidance lines. Behav Pharmacol 7: 78-84.

Reich T, Hinrichs A, Culverhouse R, Bierut L (1999). Genetic studies of alcoholism and substance dependence. Am J Hum Genet 65: 599-605.

Robinson TE (2004). Addicted rats. Science 305: 951-953.

Robinson TE, Berridge KC (2003). Addiction. Annu Rev Psychol 54: 25-53.

Schultz W (2002). Getting formal with dopamine and reward. Neuron 36: 241-263.

Shalev U, Grimm JW, Shaham Y (2002). Neurobiology of relapse to heroin and cocaine seeking: a review. Pharmacol Rev 54: 1-42.

Siegel J., Sisson DF, Driscoll P (1993). Augmenting and reducing of visual evoked potentials in Roman high- and low-avoidance rats. Physiol Behav 54: 707-711.
Steimer T, Driscoll P (2005). Inter-individual vs line/strain differences in psychogenetically selected Roman High-(RHA) and Low-(RLA) Avoidance rats: neuroendocrine and behavioural aspects. Neurosci Biobehav Rev 29: 99-112.

Sutton MA, Karanian DA, Self DW (2000). Factors that determine a propensity for cocaine-seeking behavior during abstinence in rats. Neuropsychopharmacology 22: 626-641.

Tran-Nguyen LTL, Fuchs RA, Coffey GP, Baker DA, O'Dell LE, Neisewander JL (1998). Time-dependent changes in cocaineseeking behavior and extracellular dopamine levels in the amygdala during cocaine withdrawal. Neuropsychopharmacology 19: 48-59.

Uhl GR, Liu QR, Naiman D (2002). Substance abuse vulnerability loci: converging genome scanning data. Trends in Genetics 18: 420-425.

Vanderschuren LJ, Everitt BJ (2005). Behavioral and neural mechanisms of compulsive drug seeking. Eur J Pharmacol 526: 77-88.

Vanderschuren LJ, Kalivas PW (2000). Alterations in dopaminergic and glutamatergic transmission in the induction and expression of behavioral sensitization: a critical review of preclinical studies. Psychopharmacology 151: 99-120.

Vanderschuren LJMJ, Everitt BJ (2004). Drug seeking becomes compulsive after prolonged cocaine self-administration. Science 305: 1017-1019.

Vanyukov MM, Tarter RE (2000). Genetic studies of substance abuse. Drug and Alcohol Dependence 59: 101-123.

Verheul R, van den Brink W (2000). The role of personality pathology in the aetiology and treatment of substance use disorders. Curr Opin Psychiatry 13: 163-169.

Vezina P (2004). Sensitization of midbrain dopamine neuron reactivity and the self-administration of psychomotor stimulant drugs. Neurosci Biobehav Rev 27: 827-839.

Wise RA (2004). Dopamine, learning and motivation. Nat Rev Neurosci 5: 483-494.

Zapata A, Chefer VI, Ator R, Shippenberg TS, Rocha BA (2003). Behavioural sensitization and enhanced dopamine response in the nucleus accumbens after intravenous cocaine self-administration in mice. Eur J Neurosci 17: 590-596.

Zeier H, Baettig K, Driscoll P (1978). Acquisition of DRL-20 behavior in male and female, Roman high-and low-avoidance rats. Physiol \& Behav 20: 791-793. 